\title{
Uterine fundal pressure in the second stage of labor (Kristeller maneuver) and pelvic floor dysfunction
}

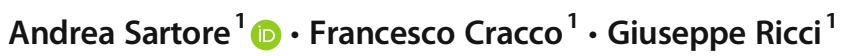 \\ Received: 16 March 2021 / Accepted: 26 April 2021 / Published online: 24 May 2021 \\ (C) The International Urogynecological Association 2021
}

\section{Dear Editor,}

We would like to comment on the article written by Takmaz and colleagues that evaluated the relationship between uterine fundal pressure during delivery and levator ani muscle defects in puerperium [1]. It is well known that uterine fundal pressure during the second stage of labor is a widely used maneuver, even if there is insufficient evidence to draw conclusions on its beneficial or harmful effects [2]. In their trial, Takmaz et al. enrolled 39 women where the fundal pressure maneuver was applied and 47 women who delivered spontaneously without the maneuver. All these primiparous women were evaluated using threedimensional transperineal ultrasonography within $48 \mathrm{~h}$ of delivery. The authors found that the Kristeller maneuver is associated with a higher risk of levator ani muscle defects, and in particular a significantly higher anteroposterior hiatal diameter during rest, Valsalva maneuver, and pelvic floor muscle contraction. These results are similar to those obtained by Youssef et al. [3], although they focused on levator ani avulsion. Takmaz et al. concluded that, to the best of their knowledge, there was no information in the literature about the functional consequences of these early findings.

In 2012, we published an article that evaluated the effects of uterine fundal pressure on pelvic floor function 3 months after vaginal delivery [4]. We enrolled 522 primiparous women divided into two groups: 297 women received the Kristeller maneuver with different indications (fetal distress, failure to progress, mother exhaustion), and 225 women constituted the control group. All the participants were questioned about symptoms of pelvic floor dysfunction (urinary and anal incontinence, dyspareunia, and perineal pain) and were examined to identify a genital prolapse

Andrea Sartore

andrea.sartore@burlo.trieste.it

1 Institute for Maternal and Child Health, I.R.C.C.S. Burlo Garofolo, Via dell'Istria 65/1, 34100 Trieste, Italy using the POP-Q system and pelvic floor function with Q-tip test, digital test, vaginal perineometry, and uroflowmetric stop test score. We did not find significant differences in terms of urinary or anal incontinence, genital prolapse, and pelvic floor strength, whereas mediolateral episiotomies, dyspareunia, and perineal pain were significantly higher in the Kristeller group. These data seem to confirm the role of episiotomies in developing perineal pain in the puerperium [5].

Apparently, our results seem to contrast with those obtained by Takmaz et al., although there is a substantial difference: we made a clinical and instrumental evaluation of the pelvic floor 3 months after delivery, whereas Takmaz et al. used only ultrasonography within 2 days of delivery. Maybe it would be useful to determine the association between perineal ultrasound and clinical evaluation in a larger population to better understand the mechanisms of perineal damage.

\section{References}

1. Takmaz T, Aydin S, Gorchiyeva I, Karasu AFG. The usual suspect: cross-sectional study of fundal pressure at second stage of delivery and the association with pelvic floor damage. Int Urogynecol J. 2020. https:// doi.org/10.1007/s00192-020-04523-x.

2. Hofmeyr GJ, Vogel JP, Cuthbert A, Singata M. Fundal pressure during the second stage of labor. Cochrane Database Syst Rev. 2017;2017(3):CD006067.

3. Youssef A, Salsi G, Cataneo I, Pacella G, Azzarone C, Paganotto $\mathrm{MC}$, et al. Fundal pressure in second stage of labor (Kristeller maneuver) is associated with increate risk of levator ani muscle avulsion. Ultrasound Obstet Gynecol. 2019;53:95-100.

4. Sartore A, De Seta F, Maso G, Ricci G, Alberico S, Borelli M, et al. The effects of uterine fundal pressure (Kristeller maneuver) on pelvic floor function after vaginal delivery. Arch Gynecol Obstet. 2012;286(5):1135-9.

5. Sartore A, De Seta F, Maso G, Pregazzi R, Grimaldi E, Giaschino S. The effects of mediolateral episiotomy on pelvic floor function after vaginal delivery. Obstet Gynecol. 2004;103(4):669-73.

Publisher's note Springer Nature remains neutral with regard to jurisdictional claims in published maps and institutional affiliations. 